\title{
Survivin regulates the expression of VEGF-C in lymphatic metastasis of breast cancer
}

\author{
Xiaopeng Cai', Shuai Ma', Ming Gu' ${ }^{1}$, Cong $\mathrm{Zu}^{1,2}$, Wenzhi $\mathrm{Qu}^{3}$ and Xinyu Zheng ${ }^{1,2^{*}}$
}

\begin{abstract}
Background: As a known regulator of apoptosis, survivin has positive relationship with lymphatic metastasis in breast cancer. This study aims to detect the difference in expression between survivin and vascular endothelial growth factor-C (VEGF-C) in treated breast cancer cells and tissues, and to analyze the correlation among survivin, VEGF-C and lymphatic metastasis.

Methods: Plasmid with survivin and VEGF-C shRNA and lentivirus with survivin gene were constructed and transfected into breast cancer cell ZR-75-30. Then the expressions of the two genes were examined using western blot analysis and real-time PCR. The change of invasiveness of breast cancer cells was assessed using matrigel invasion assay. Using immunohistochemistry, the expression of survivin and VEGF-C were analyzed in 108 clinical breast cancer cases with breast cancer tissue and lymph node.

Results: Survivin regulated the expression of VEGF-C at both protein and mRNA levels in breast cancer cells. Immunohistochemical analysis showed that the level of VEGF-C expression was significantly related with that of survivin in breast cancer tissues $(p<0.05)$. VEGF-C was found to participate in the process of breast cancer cells invasion mediated by survivin. The co-expression of the two and the single expression of any one took significant difference in positive lymph node $(p<0.05)$.

Conclusions: Survivin takes an important part in regulating the expression of VEGF-C. VEGF-C could influence the invasive ability mediated by survivin. The co-expression of survivin and VEGF-C is more statistically significant to assess lymphatic metastasis in breast cancer.

Virtual slides: The virtual slide(s) for this article can be found here: http://www.diagnosticpathology.diagnomx.eu/ vs/9193530897100952
\end{abstract}

Keywords: Survivin, VEGF-C, Breast cancer, Lymphatic metastasis

\section{Background}

Breast cancer is the most frequently diagnosed cancer and the leading cause of cancer death in females, accounting for $23 \%$ ( 1.38 million) of the total new cancer cases and $14 \%(458,400)$ of the total cancer deaths in 2008 worldwide [1]. More than half of breast cancers are associated with axillary nodal involvement. Metastasis and recurrence severely affect the quality and length of lives of breast cancer patients. In the NCCN clinical

\footnotetext{
* Correspondence: xyzheng@mail.cmu.edu.cn

'Department of Breast Surgery, First Affiliated Hospital, China Medical University, No. 155 North Nanjing Street, Shenyang, Liaoning Province 110001, China

¿2ab 1, Cancer Institute, China Medical University, Shenyang, Liaoning

Province 110001, China

Full list of author information is available at the end of the article
}

practice guidelines of breast cancer, lymphatic metastasis is considered the main criteria for clinical prognosis and target of systemic treatment. Axillary lymph node status is the most important prognostic factor in breast cancer, and prognosis declines with increasing number of tumorpositive lymph nodes [2].

Lymphatic metastasis is one of the most important pathways of breast cancer systemic metastasis, and is closely related to prognosis and therapy plans for breast cancer patients. Many pathways have been suggested to be involved in the process of breast cancer lymphatic metastasis. And some markers, such as EGFR [3] and BCRP [4], could be detected as the predictable target of breast cancer lymphatic metastasis. Some researches have indicated that survivin and vascular endothelial

\section{Biomed Central}

(c) 2012 Cai et al.; licensee BioMed Central Ltd. This is an Open Access article distributed under the terms of the Creative Commons Attribution License (http://creativecommons.org/licenses/by/2.0), which permits unrestricted use, distribution, and reproduction in any medium, provided the original work is properly cited. 
growth factor-C (VEGF-C) may take part in the course of lymphatic metastasis of breast cancer.

Survivin is one of the inhibitors of apoptosis protein (IAP). It regulates two important cellular processes including inhibition of cell apoptosis and promoting cell proliferation [5]. High levels of survivin mediate resistance of cancer cells to a series of anti-cancer drugs [6], and it has been shown that up-regulation of survivin confers resistance of cancer cells to radiotherapy $[7,8]$. Several researches in breast cancer, gastric cancer, oral squamous cell carcinoma and colorectal cancer have shown that the expression of survivin is significantly related to lymphatic metastasis, and that survivin is the prognostic marker for these cancers [9-13]. However, how survivin controls lymphatic metastasis remains elusive.

VEGF-C, also called lymphatic vessel growth factor, is a lymphatic endothelial cell-stimulating factor. VEGF-C affects blood vessel and lymphatic vessel through vascular endothelial growth factor receptor-2 (VEGFR-2) and vascular endothelial growth factor receptor-3 (VEGFR-3), respectively, to improve tumor growth and metastasis [14]. High levels of VEGF-C have been detected inside or around tumors lymphatic vessels, by which lymphatic and even distal metastasis are promoted [15]. High levels of VEGF-C also lead to lymphatic vessel formation in lymph nodes [16]. Many researches have also demonstrated that VEGF-C is involved in lymphatic invasion in esophageal cancer, breast cancer, non-small cell lung cancer, and colorectal cancer [17-20].

It has been suggested that both survivin and VEGF-C play important roles in tumor lymphatic metastasis; however, studies on the relationship between the two are scarce. In this study, we discuss the relationship between survivin and VEGF-C in breast cancer and the pathway by which survivin may affect breast cancer lymphatic metastasis.

\section{Material and methods \\ Clinical samples}

A total of 108 breast cancer patients aged 32 to 63 with a mean age of 48 were involved in this study. All patients were examined and monitored from 20092011 in the First Affiliated Hospital of China Medical University in Shenyang, Liaoning province, China. Breast cancer was diagnosed and classified into various stages according to the International Union Against Cancer (UICC) and the TNM classification system published by the American Joint Committee on Cancer (AJCC). Clinical information obtained from the records and the histopathology reports included age, first diagnosis, tumor size and grade, oestrogen-receptor (ER) and progesterone-receptor (PR) status, and lymph nodal involvement.

\section{Cell culture}

Human breast cancer cell line ZR-75-30 was preserved from Cell Resoure Center of Shanghai Life Science Research Institute, Chinese Academy of Sciences. And it was cultured in RPM1640 medium (Invitrogen Corporation, Carlsbad, California, USA) supplemented with $50 \mu \mathrm{g} / \mathrm{ml}$ penicillin, $50 \mu \mathrm{g} / \mathrm{ml}$ streptomycin and $10 \%$ fetal bovine serum at $37^{\circ} \mathrm{C}$ in a $5 \% \mathrm{CO}_{2}$ environment. Long phase cells were collected after trypsin digestion by centrifugation for 5 minute at $1,000 \mathrm{rpm}$, re-suspended in phosphate buffered saline (PBS), and counted using a haemocytometer.

\section{Construction and transfection of plasmid-ShRNA and lentivirus}

Plasmids with survivin-shRNA and VEGF-C-shRNA were constructed by Shanghai GennePharma Co., Ltd, and lentivirus with survivin gene was constructed by Shanghai GeneChem Co., Ltd. Plasmid-survivin-shRNA and plasmid-VEGF-C-shRNA, $10 \mu \mathrm{g}$ shRNA and $25 \mu \mathrm{l}$ Lipofectamine 2000 (Invitrogen Corporation, Carlsbad, California, USA) were mixed in $1350 \mu 1640$ medium without FBS and transfected into brest cancer cells. The mixture were added into $25-\mathrm{cm}^{2}$ culture flask that was previously plated with $1 \times 10^{6}$ ZR-75-30 breast cancer cells. Culture medium was replaced with complete 1640 medium once six hours post inoculation and cells were collected after another 28 hours. Protein and RNA were extracted for western blot and real-time PCR analysis, respectively.

Lentivirus with survivin gene was transfected into cells at an MOI of 20 and $0.75 \mu$ polyprene were added into each well of the 6-well plate containing $2 \times 10^{5}$ ZR-75-30 cells. Medium was replaced after 8 hours, and then cells were cultured at $37^{\circ} \mathrm{C}$ in a $5 \% \mathrm{CO}_{2}$ environment.

\section{Western blot analysis}

Proteins were separated by SDS-PAGE, transferred onto nitrocellulose membranes, and detected using relevant primary antibody and appropriate secondary antibody. Primary antibodies included: anti-survivin (mouse monoclonal, Santa Cruz, CA, USA), anti-VEGF-C (rabbit polyclonal, ABGENT, San Diego, CA, USA) and anti- $\beta$-actin (mouse monoclonal, Santa Cruz, CA, USA).

\section{RNA isolation and Real-time polymerase chain reaction}

Total RNA was extracted using the guanidinium thiocyanate-phenol-chloroform method. RNA yield and purity were determined photometrically (BioPhotometer, Eppendorf, Germany). Reverse transcription was performed. Survivin and VEGF-C were amplified using real time PCR. A total of $10 \mathrm{ng}$ of reverse-transcribed total RNA was used as the template, and PCR reaction contained $20 \mathrm{pmol} / \mathrm{ml}$ of each sense and antisense primer (Table 1) and SYBR Premix Ex Taq II (TaKaRa, Dalian, 
Table 1 Primers used for real-time PCR

\begin{tabular}{llll}
\hline Primer & & 5/-3/ sequence & $\begin{array}{l}\text { Size of } \\
\text { PCR (bp) }\end{array}$ \\
\hline Survivin & forward & TCATAGAGCTGCAGGGTGGATTGT & 114 \\
& $\begin{array}{l}\text { reverse } \\
\text { VEGF-C }\end{array}$ & AGTAGGGTCCACAGCAGTGTTGA & \\
& forward & AACCTCCATGTGTGTCCGTC & 156 \\
GAPDH & forward & ACAGTCCATGCCATCACTGCC & 266 \\
& reverse & GCCTGCTTCACCACCTTCTTG & \\
\hline
\end{tabular}

Shenyang, China) in a final volume of $20 \mu \mathrm{l}$. An ABI PRISM 7700 Sequence Detection System Instrument (Applied Biosystems) was used for the amplification. Cycling conditions consisted of an initial denaturation step at $95^{\circ} \mathrm{C}$ for $10 \mathrm{~min}$ as a 'hot start', followed by 40 cycles of $95^{\circ} \mathrm{C}$ for $15 \mathrm{~s}$, annealing temperature for $30 \mathrm{~s}, 72^{\circ} \mathrm{C}$ for $30 \mathrm{~s}$, and a final extension at $72^{\circ} \mathrm{C}$ for $10 \mathrm{~min}$. GAPDH was used in each experiment as an endogenous control. Relative quantification for a gene was expressed as fold changes over the control group. Fold changes were calculated using the $2^{-\Delta \Delta \mathrm{Ct}}$ method.

\section{Matrigel invasion assay}

The migration capacity of breast cancer cells was determined in vitro using Transwell Chambers (Corning, NY, USA) in which the two chambers were separated with matrigel coated polycarbonate membrane $(6.5-\mathrm{mm}$ diameter inserts, $8 \mu \mathrm{m}$ pore size). Breast cancer cells $\left(5 \times 10^{5} / \mathrm{ml}\right.$ serum-free medium) were placed in the upper chamber $(200 \mu \mathrm{l})$. The lower chamber contained medium alone $(500 \mu \mathrm{l})$. Chambers were assembled and kept in an incubator for 24 hours. At the desired time point, cells from the upper surface of the membrane were removed with gentle swabbing and the migrant cells on the lower surface of the membrane were fixed by methanol and stained with crystal violet. Then membranes were washed with PBS and mounted onto slide

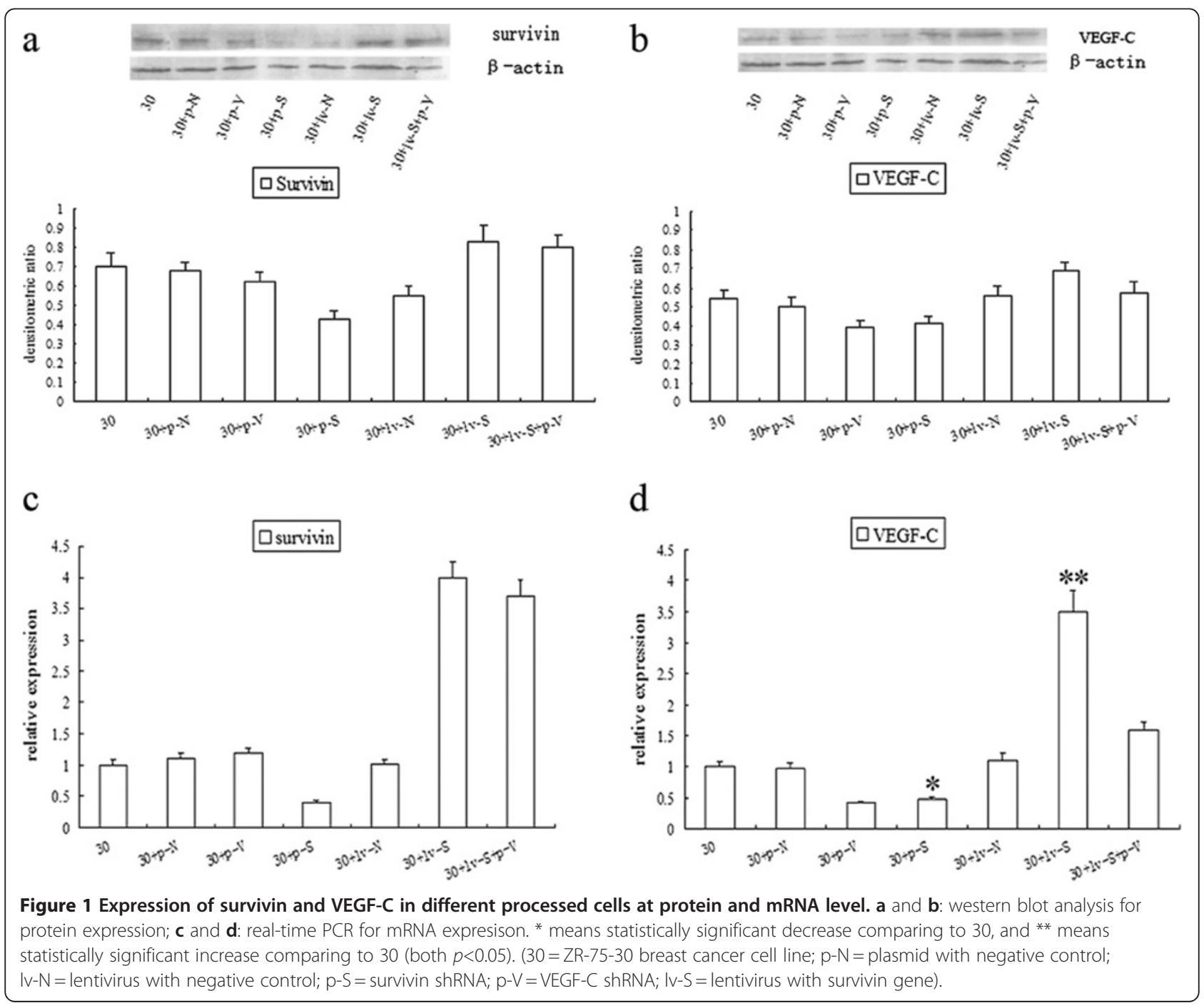


glasses. The membranes were visualized microscopically (Olympus BX41) and cellular migration per sample was determined by counting the number of stained cells in at least four to five randomly selected fields. Data are presented as mean number of the migrating cells \pm SD per microscopic field per sample. Each cell migration experiment was repeated at least three times.

\section{Immunohistochemical analysis}

Immunohistochemistry was carried out on paraffinembedded tumor specimens fixed in $4 \%$ buffered formalin. Four-micrometer-thick histological slides were de-paraffinized in xylol and heated in $0.01 \mathrm{M}$ citrate buffer for $25 \mathrm{~min}$ in a microwave oven. After cooled for $20 \mathrm{~min}$ and washed in PBS, endogenous peroxidase was detected by incubating samples with PBS containing $10 \%$ normal goat serum for $30 \mathrm{~min}$. Then the sections were incubated with each primary antibody overnight at $4^{\circ} \mathrm{C}$. The primary antibodies were anti-survivin (mouse monoclonal, Santa Cruz, CA., USA, 1:10) and anti-VEGF-C (rabbit polyclonal, Abcam Inc, Cambridge, MA, UK, 1:200). A further wash in PBS was followed by treatment with peroxidaselabeled polymer conjugated to goat anti-mouse or antirabbit immunogloblins (Envison + kit; Dako, Glostrup, Denmark) as the secondary antibody for $10 \mathrm{~min}$ at room temperature. The staining was visualized with diaminobenzidine (DAB), followed by counterstaining with hematoxylin. For a negative control, PBS was substituted for the primary antibody.
The degree of immunohistochemical staining was recorded on a scale of $0-3$ according to the percentages of staining and distributions within the cytoplasm. Tumors were scored on a four-tier system: less than $10 \%$ of cancer cells staining was designated negative (as degree 0), 10$20 \%$ positive staining was scored as degree $1+, 21-50 \%$ positive staining was scored as degree $2+$, and $51-100 \%$ positive staining was scored as degree $3+$. We checked at least five $200 \times$ visual fields for one glass slide under microscope, counted the percentage of positive cells in every fields and got the mean percentage of positive cells in a glass slide. At last, we got the score of the glass slide on the base of percentage.

\section{Statistical analysis}

Data was expressed as the means of at least three different experiments $\pm \mathrm{SD}$. The results were analyzed by chisquare test and Spearman analysis. $p<0.05$ was considered statistically significant.

\section{Results}

\section{Transfection of plasmid and lentivirus}

Plasmids with survivn shRNA and VEGF-C shRNA contained green fluorescent protein (GFP) were transfected into cells using the method mentioned above. The transfection efficiency was about $50 \%-70 \%$ after 24 hours.

Lentivirus-survivin with GFP was transfected into cells using the method mentioned above. The transfection efficiency was nearly $100 \%$.

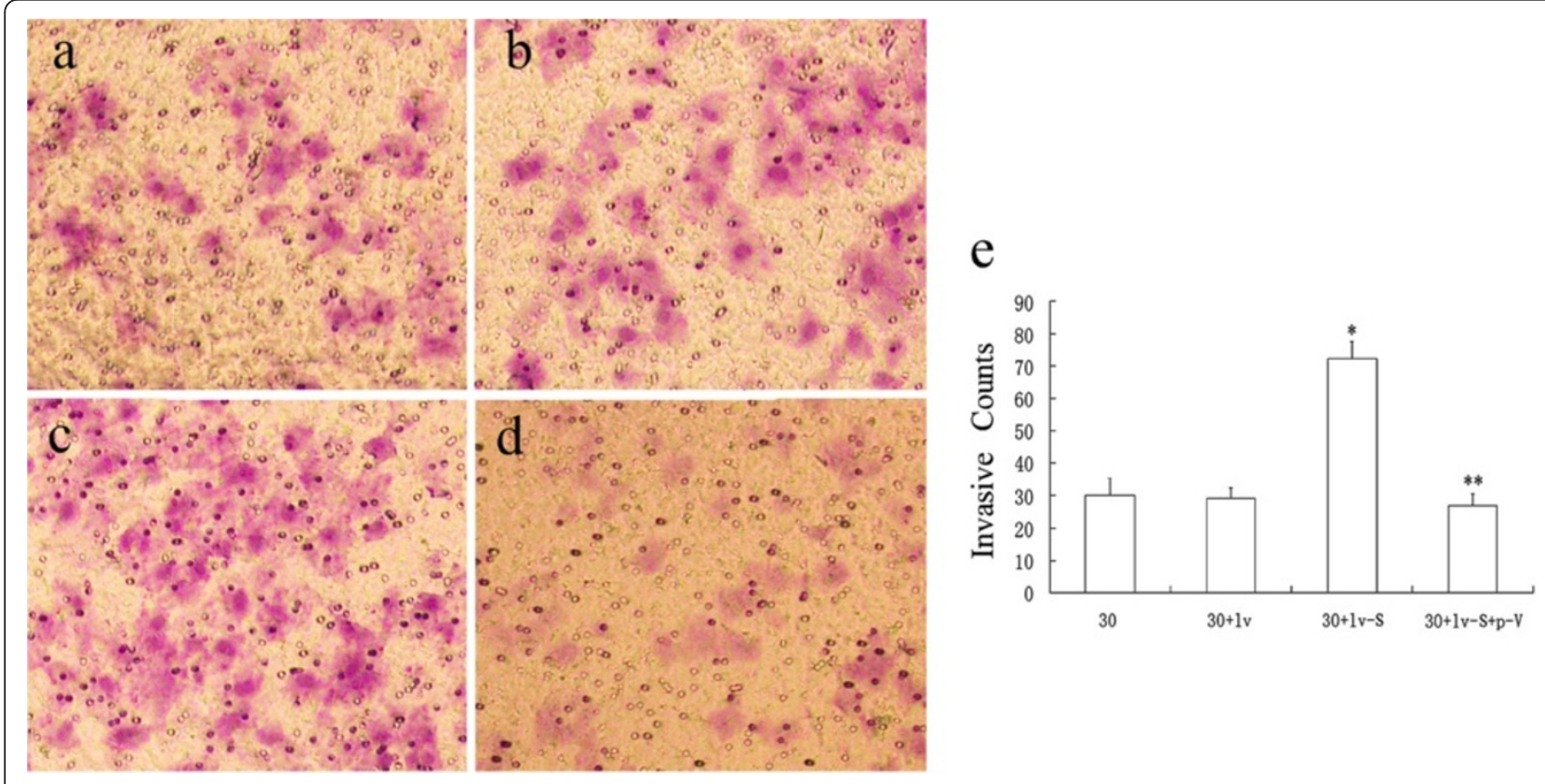

Figure 2 Matrigel invasion assay from different processed cells. a,b,c and $\mathbf{d}$ show the invasive cells of group 30, group $30+\mathrm{IV}$, group $30+\mathrm{IV}-\mathrm{S}$ and group $30+\mathrm{IV}-\mathrm{S}+\mathrm{p}-\mathrm{V}$ under a microscope(200X). e shows the mean number counted from above visual field. * means statistically significant different between $30+\mathrm{lv}-\mathrm{S}$ and ZR-75-30 cells. ${ }^{* *}$ means significant different between $30+\mathrm{lv}-\mathrm{S}$ and $30+\mathrm{lv}-\mathrm{S}+\mathrm{p}-\mathrm{V}(\mathrm{both} p<0.05)$. 


\section{Expressions of VEGF-C and survivin were positively correlated}

In ZR-75-30 cells, when survivin was down-regulated, VEGF-C was down-regulated with western blot method. When survivin was up-regulated, VEGF-C had a higher expression level than that in normal cells. In ZR-75-30 cells over-expressing survivin, VEGF-C expression level also decreased when survivin was down-regulated. Realtime PCR showed that the level of VEGF-C mRNA positively correlated with the level of survivin mRNA (Figure 1).

\section{Survivin changed invasive ability of cells through VEGF-C} In the matrigel invasion assay, breast cancer cells with high levels of survivin were more invasive than those with low levels of survivin, which suggested that survivin played an important role in tumor cells migration. However, down-regulated VEGF-C in these cells significantly reduced the number of breast cancer cells that could migrate through the polycarbonate membrane (Figure 2).

\section{Survivin and VEGF-C expression in tumor tissue and lymph node}

Survivin and VEGF-C mainly localized in the cytoplasm, but could also be detected in the nuclei with nuclearspecific dye. Survivin was expressed in the breast cancer tissue of $83.3 \%$ of the patients, among which degree $1-3+$ were expressed at $26.7 \%, 50.0 \%, 23.3 \%$. In the same group of patients, VEGF-C was expressed at $77.8 \%$ and degree 1$3+$ were $28.6 \%, 53.6 \%, 17.9 \%$. In the lymph node tissue, both survivin and VEGF-C were expressed at higher levels in positive LN than in negative LN (Figure 3).

\section{Pathological analysis of patients}

Survivin and VEGF-C were expressed at higher levels in patients with lymphatic metastasis, and stage III, IV breast cancers (Table 2). The expression levels were also statistically different in tumors of different sizes. However, there were no differences in the expression of the two genes in patients with different age, histological grade, pathological style, or ER/PR status. The results showed that higher

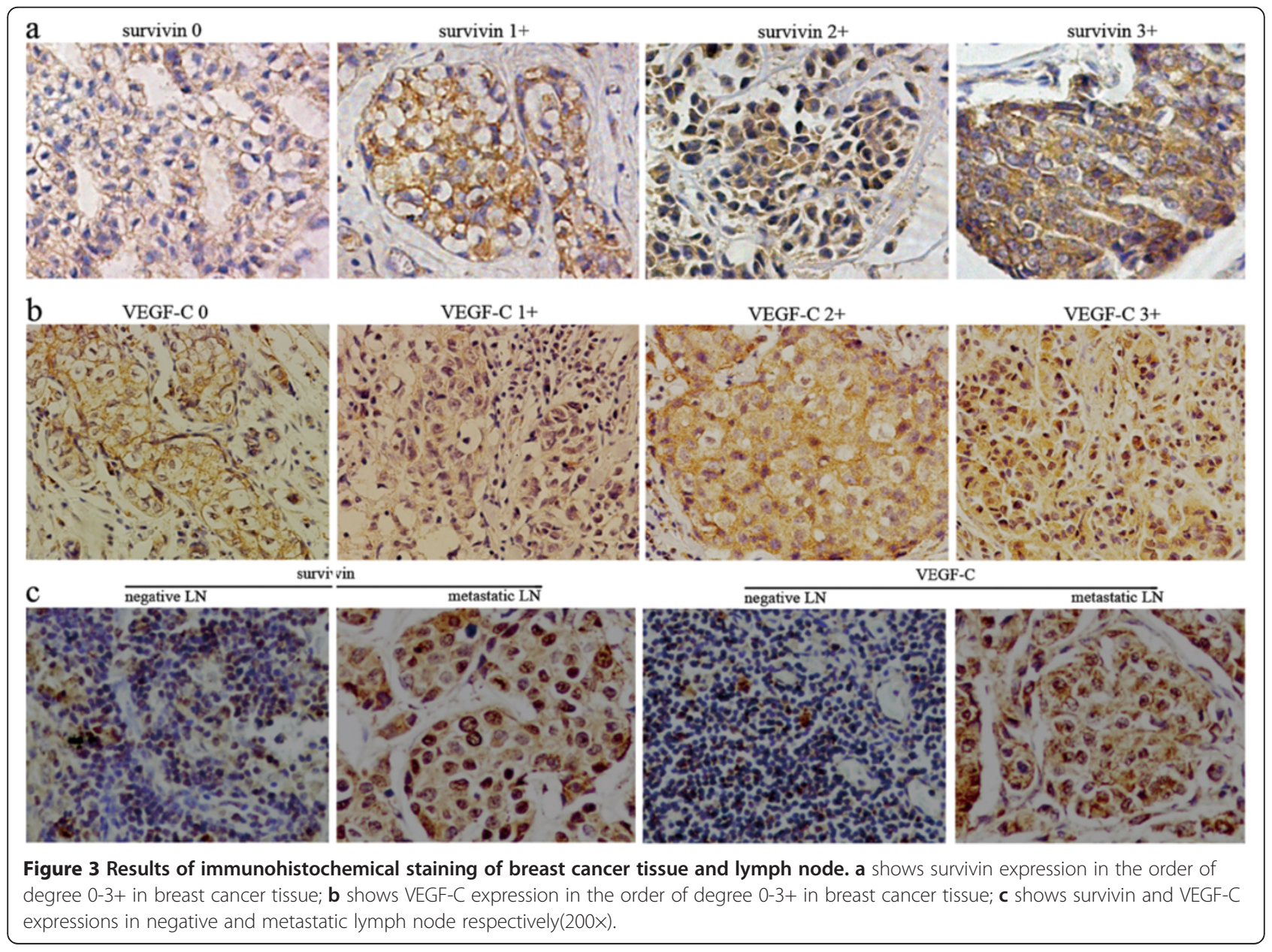


Table 2 Association of survivin and VEGF-C protein expression with clinicopathological features in breast cancer patients

\begin{tabular}{|c|c|c|}
\hline Variable & $n$ & Survivin- \\
\hline \multicolumn{3}{|l|}{ Age } \\
\hline$\leq 45$ years & 36 & 6 \\
\hline$>45$ years & 72 & 12 \\
\hline \multicolumn{3}{|l|}{ Tumor size } \\
\hline $\mathrm{T} 1$ & 39 & 12 \\
\hline $\mathrm{T} 2$ & 60 & 6 \\
\hline T3 & 9 & 0 \\
\hline
\end{tabular}

Histological grade

I+II

III

Pathological style

ISC

IC

$99 \quad 15$

9

3

Lymph node metastasis

\section{Negative}

Positive

C-erBb-2

positive $(3+)$

negative $(0-2+)$

ER

$\begin{array}{llll}\text { positive } & 63 & 9 & 54 \\ \text { negative } & 45 & 9 & 36\end{array}$

PR

$\begin{array}{clll}\text { positive } & 54 & 9 & 45 \\ \text { negative } & 54 & 9 & 45\end{array}$

TNM stage

$\begin{array}{ccc}\text { I, II } & 72 & 18 \\ \text { III, IV } & 36 & 0\end{array}$

ISC, in situ carcinoma; IC, invasive carcinoma.

expression was detected in $\mathrm{C}$-erBb-2 positive but not in $\mathrm{C}$-erBb-2 negative patients.

There was significant difference between the levels of VEGF-C and survivin expression $(p<0.05)$ (Table 3 ). When the level of survivin expression increased from degree 0 to 3 , the level of VEGF-C expression increased correspondingly. And the Pearson coefficient of contingency

Table 3 Relationship of expression extent between surivivin and VEGF-C

\begin{tabular}{lccccc}
\hline & VEGF-C $0-1+$ & VEGF-C 2+ & VEGF-C 3+ & $\mathbf{X}^{\mathbf{2}}$ & $\boldsymbol{p}$ \\
\hline Survvin 0-1+ & 30 & 9 & 3 & 38.769 & 0.000 \\
Survivin 2+ & 12 & 30 & 3 & & \\
Survivin 3+ & 6 & 6 & 9 & & \\
\hline
\end{tabular}

$\mathrm{C}=0.514$, which means an actual expression relationship between VEGF-C and survivin.

In the patients with co-expression of survivin and VEGF-C, the lymph node positive rate is higher than the patients with the single or none expression of survivin and VEGF-C $(p<0.05)$ (Table 4$)$. This result indicated that survivin co-operated with VEGF-C in lymphatic metastasis.

Table 4 Relationship of co-expression of survivin and VEGF-C with lymph node involvement

\begin{tabular}{ccccc}
\hline & Survivin(-/+)/VEGF-C(-/+) & Survivin(+)\&VEGF-C(+) & $\mathbf{X}^{\mathbf{2}}$ & $\boldsymbol{p}$ \\
\hline LN- & 12 & 18 & 4.985 & 0.026 \\
LN+ & 15 & 63 & & \\
\hline
\end{tabular}




\section{Discussion}

The expression of survivin is high during fetal development but low in healthy adult tissues. However, in most malignant tumors, the expression of survivin increases. As a result, survivin has been considered a potential tumor marker and an important therapeutic target [5]. Studies show that the expression of survivin in many kinds of tumors correlates with lymphatic metastasis. Our results suggest that survivin may influence breast cancer lymphatic metastasis and distal invasion through VEGF-C.

Researches on different tumors have indicated that the up-regulation of VEGF-C promotes tumor lymphatic vessel formation and increases lymph node metastasis. VEGF-C could form lots of lymphatic vessel inside or around the tumor, by which promoting tumor metastasis to lymph node and even distal organs [15]. Then it could make a good condition for advanced metastasis and diffusion.

We showed that the protein and mRNA expression of VEGF-C are controlled by survivin. So, there must be a notal point by which the expression of VEGF-C could be regulated by survivin. Cox-2 activation is highly correlated with VEGF-C expression [21], and through its downstream molecules, cox-2 is able to up-regulate the expression of VEGF-C in cancer cells [22,23]. As an important regulator of apoptosis, cox-2 is usually overexpressed with survivin in hepatocellular carcinoma, surperficial urothelial carcinoma and endometrial carcinoma [24-26]. It is possible that cox-2 may be the notal point to link survivin and VEGF-C expressions.

It has been suggested that the interaction of XIAP and survivin promotes the invasion of tumor cells and enhances the metastatic spread in vivo [27]. Khan et al. have shown that synthetic survivin enhances the proliferation, drug resistance, and cellular invasion of tumor cells [28]. It has been suggested that VEGF-C could promote the VEGFR3 positive tumor cells invade to lymphatic vessels through autocrine and CCR-7 dependent paracrine mechanism [29]. VEGF-C was also proven to control tumor cells growth and invasion by atuocrine mechanism in the carcinoma of gallbladder [30]. In accordance with this result, our results show that the invasiveness of breast cancer cell increases when survivin is over-expressed, and significantly decreases when survivn is over-expressed while VEGF-C is down-regulated. So VEGF-C may play an important role in enhancing the invasiveness in tumor cells caused by survivin. On the other hand, in positive lymph node, survivin and VEGF-C both express at high levels, which may indicate that both of them play important roles in lymphatic metastasis and invasion in breast cancer.

Several researches found that survivin and VEGF-C took high level expression in the breast cancer, also had positive relationship with positive lymphatic metastasis respectively $[9,31,32]$. And not only in the primary breast tumor, survivin was also found high level expression in circulating tumor cells in peripheral blood through RT-PCR ELISA method [33]. It suggested that the tumor cells with survivin high expression showed great invasive and metastatic ability. In our study, it has been proven that survivin and VEGF-C both are closely related with lymphatic metastasis in different tumors. We show in our study that survivin and VEGF-C expression are positively correlated, and the co-expression of the two is also positively correlated with positive lymph node. This result supports the conclusion based on previous finding that changes in survivin expression induce the changes in VEGF-C expression.

\section{Conclusion}

As a conclusion, survivin is related with breast cancer lymphatic metastasis. It gets correlation with the rate of lymph node metastasis and the invasive ability of breast cancer cells. VEGF-C may play an important role in these processes. Survivin can influenced the expression of VEGF-C to reduce breast cancer lymphatic metastasis and invasion, which helps to decrease death risk of breast cancer. Meanwhile, survivin and VEGF-C can be used simultaneously as important markers to access lymphatic metastasis and distal invasion of breast cancer.

\section{Competing interests}

All authors declare no competing interests.

\section{Authors' contributions}

$X C$ and SM carried out the design and western blot of this research, MG and CZ participated in real-time PCR and immunohistochemistry of this research, WQ performed the Statistical Analysis, XZ was the director of this research and helped to draft the manuscript. All authors read and approved the final manuscript.

\section{Acknowledgements}

This work was partially supported by grants from the Scientific Research Foundation for Returned Scholars of Ministry of Education of China (2008), Hi-Tech Research Development Program of China (863 Program, 2006AA02Z493) and the National Natural Science Foundation of China (No. 81071900 and 81172199 ).

\section{Author details}

${ }^{1}$ Department of Breast Surgery, First Affiliated Hospital, China Medical University, No. 155 North Nanjing Street, Shenyang, Liaoning Province 110001, China. 'Lab 1, Cancer Institute, China Medical University, Shenyang, Liaoning Province 110001, China. ${ }^{3}$ Department of Breast Surgery, Fourth Affiliated Hospital, China Medical University, Shenyang, Liaoning Province 110001, China.

Received: 11 April 2012 Accepted: 8 May 2012

Published: 18 May 2012

\section{References}

1. Jemal A, Bray F, Center MM, Ferlay J, Ward E, Forman D: Global cancer statistics. CA Cancer J Clin 2011, 61:69-90.

2. Fisher B, Bauer M, Wickerham DL, Redmond CK, Fisher ER, Cruz AB, Foster $R$, Gardner B, Lerner H, Margolese R, et al: Relation of number of positive axillary nodes to the prognosis of patients with primary breast cancer. An NSABP update. Cancer 1983, 52:1551-1557. 
3. Lv N, Xie X, Ge Q, Lin S, Wang X, Kong Y, Shi H, Wei W: Epidermal growth factor receptor in breast carcinoma: association between gene copy number and mutations. Diagn Pathol 2011, 6:118.

4. Xiang L, Su P, Xia S, Liu Z, Wang Y, Gao P, Zhou G: ABCG2 is associated with HER-2 expression, lymph node metastasis and clinical stage in breast invasive ductal carcinoma. Diagn Pathol 2011, 6:90.

5. Ryan BM, O'Donovan N, Duffy MJ: Survivin: a new target for anti-cancer therapy. Cancer Treat Rev 2009, 35:553-562.

6. Pennati M, Folini M, Zaffaroni N: Targeting survivin in cancer therapy. Expert Opin Ther Targets 2008, 12:463-476.

7. Rodel C, Haas J, Groth A, Grabenbauer GG, Sauer R, Rodel F: Spontaneous and radiation-induced apoptosis in colorectal carcinoma cells with different intrinsic radiosensitivities: survivin as a radioresistance factor. Int J Radiat Oncol Biol Phys 2003, 55:1341-1347.

8. Chakravarti A, Zhai GG, Zhang M, Malhotra R, Latham DE, Delaney MA, Robe $P$, Nestler $U$, Song $Q$, Loeffler J: Survivin enhances radiation resistance in primary human glioblastoma cells via caspase-independent mechanisms. Oncogene 2004, 23:7494-7506.

9. Al-Joudi FS, Iskandar ZA, Hasnan J, Rusli J, Kamal Y, Imran AK, Ahmed M, Zakaria J: Expression of survivin and its clinicopathological correlations in invasive ductal carcinoma of the breast. Singapore Med J 2007, 48:607-614

10. $\mathrm{Da} C L$, Xin $Y$, Zhao J, Luo XD: Significance and relationship between Yesassociated protein and survivin expression in gastric carcinoma and precancerous lesions. World J Gastroenterol 2009, 15:4055-4061.

11. Kim YH, Kim SM, Kim YK, Hong SP, Kim MJ, Myoung H: Evaluation of survivin as a prognostic marker in oral squamous cell carcinoma. J Oral Pathol Med 2010, 39:368-375.

12. Su L, Wang $Y$, Xiao $M$, Lin $Y, Y u L$ : Up-regulation of survivin in oral squamous cell carcinoma correlates with poor prognosis and chemoresistance. Oral Surg Oral Med Oral Pathol Oral Radiol Endod 2010, 110:484-491.

13. Xiaoyuan C, Longbang C, Jinghua W, Xiaoxiang G, Huaicheng G, Qun Z, Haizhu S: Survivin: a potential prognostic marker and chemoradiotherapeutic target for colorectal cancer. Ir J Med Sci 2010, 179:327-335.

14. Lohela M, Bry M, Tammela T, Alitalo K: VEGFs and receptors involved in angiogenesis versus lymphangiogenesis. Curr Opin Cell Biol 2009, 21:154-165

15. Guo B, Zhang Y, Luo G, Li L, Zhang J: Lentivirus-mediated small interfering RNA targeting VEGF-C inhibited tumor lymphangiogenesis and growth in breast carcinoma. Anat Rec (Hoboken) 2009, 292:633-639.

16. Achen MG, Stacker SA: Molecular control of lymphatic metastasis. Ann N Y Acad Sci 2008, 1131:225-234.

17. Tanaka T, Ishiguro H, Kuwabara Y, Kimura M, Mitsui A, Katada T, Shiozaki M, Naganawa Y, Fujii Y, Takeyama H: Vascular endothelial growth factor C (VEGF-C) in esophageal cancer correlates with lymph node metastasis and poor patient prognosis. J Exp Clin Cancer Res 2010, 29:83.

18. Ran S, Volk L, Hall K, Flister MJ: Lymphangiogenesis and lymphatic metastasis in breast cancer. Pathophysiology 2010, 17:229-251.

19. Feng Y, Wang W, Hu J, Ma J, Zhang Y, Zhang J: Expression of VEGF-C and VEGF-D as significant markers for assessment of lymphangiogenesis and lymph node metastasis in non-small cell lung cancer. Anat Rec (Hoboken) 2010, 293:802-812.

20. Zhang C, Hao L, Wang L, Xiao Y, Ge H, Zhu Z, Luo Y, Zhang Y: Elevated IGFIR expression regulating VEGF and VEGF-C predicts lymph node metastasis in human colorectal cancer. BMC Cancer 2010, 10:184.

21. Eibl G, Bruemmer D, Okada Y, Duffy JP, Law RE, Reber HA, Hines OJ: PGE(2) is generated by specific COX-2 activity and increases VEGF production in COX-2-expressing human pancreatic cancer cells. Biochem Biophys Res Commun 2003, 306:887-897

22. Hsieh CY, Chen CA, Chou CH, Lai KP, Jeng YM, Kuo ML, Wei LH: Overexpression of Her-2/NEU in epithelial ovarian carcinoma induces vascular endothelial growth factor $C$ by activating NF-kappa B: implications for malignant ascites formation and tumor lymphangiogenesis. J Biomed Sci 2004, 11:249-259.

23. Su JL, Shih JY, Yen ML, Jeng YM, Chang CC, Hsieh CY, Wei LH, Yang PC, Kuo ML: Cyclooxygenase-2 induces EP1- and HER-2/Neu-dependent vascular endothelial growth factor-C up-regulation: a novel mechanism of lymphangiogenesis in lung adenocarcinoma. Cancer Res 2004, 64:554-564.
24. Yang $Y$, Zhu J, Gou H, Cao D, Jiang M, Hou M: Clinical significance of Cox2, Survivin and $\mathrm{BCl}-2$ expression in hepatocellular carcinoma (HCC). Med Oncol 2011, 28:796-803.

25. Yildirim U, Erdem H, Kayikci A, Sahin AF, Uzunlar AK, Albayrak A: Cyclooxygenase-2 and survivin in superficial urothelial carcinoma of the bladder and correlation with intratumoural microvessel density. J Int Med Res 2010, 38:1689-1699.

26. Lambropoulou M, Papadopoulos N, Tripsianis G, Alexiadis G, Pagonopoulou $\mathrm{O}$, Kiziridou A, Liberis V, Kakolyris S, Chatzaki E: Co-expression of survivin, c-erbB2, and cyclooxygenase-2 (COX-2): prognostic value and survival of endometrial cancer patients. J Cancer Res Clin Oncol 2010, 136:427-435.

27. Mehrotra S, Languino LR, Raskett CM, Mercurio AM, Dohi T, Altieri DC: IAP regulation of metastasis. Cancer Cell 2010, 17:53-64.

28. Khan S, Aspe JR, Asumen MG, Almaguel F, Odumosu O, Acevedo-Martinez S, De Leon M, Langridge WH, Wall NR: Extracellular, cell-permeable survivin inhibits apoptosis while promoting proliferative and metastatic potential. Br J Cancer 2009, 100:1073-1086.

29. Issa A, Le TX, Shoushtari AN, Shields JD, Swartz MA: Vascular endothelial growth factor-C and C-C chemokine receptor 7 in tumor cell-lymphatic cross-talk promote invasive phenotype. Cancer Res 2009, 69:349-357.

30. Chen $Y$, Jiang L, She F, Tang N, Wang X, Li X, Han S, Zhu J: Vascular endothelial growth factor- $C$ promotes the growth and invasion of gallbladder cancer via an autocrine mechanism. Mol Cell Biochem 2010, 345:77-89.

31. Skobe $M$, Hawighorst $T$, Jackson DG, Prevo R, Janes $L$, Velasco P, Riccardi $L$, Alitalo K, Claffey K, Detmar M: Induction of tumor lymphangiogenesis by VEGF-C promotes breast cancer metastasis. Nat Med 2001, 7:192-198.

32. Koyama Y, Kaneko K, Akazawa K, Kanbayashi C, Kanda T, Hatakeyama K: Vascular endothelial growth factor- $C$ and vascular endothelial growth factor-d messenger RNA expression in breast cancer: association with lymph node metastasis. Clin Breast Cancer 2003, 4:354-360.

33. Yie SM, Luo B, Ye NY, Xie K, Ye SR: Detection of Survivin-expressing circulating cancer cells in the peripheral blood of breast cancer patients by a RT-PCR ELISA. Clin Exp Metastasis 2006, 23:279-289.

doi:10.1186/1746-1596-7-52

Cite this article as: Cai et al:: Survivin regulates the expression of VEGF-C in lymphatic metastasis of breast cancer. Diagnostic Pathology 2012 7:52.

\section{Submit your next manuscript to BioMed Central and take full advantage of:}

- Convenient online submission

- Thorough peer review

- No space constraints or color figure charges

- Immediate publication on acceptance

- Inclusion in PubMed, CAS, Scopus and Google Scholar

- Research which is freely available for redistribution

Submit your manuscript at www.biomedcentral.com/submit
C) Biomed Central 